\title{
Internal and External Collaborative Technology Adoption: A Focus on a European and an Emerging \\ Countries' Gaps Based on the Adaptive Structuration Theory
}

\author{
Marc Diviné $^{1}$ and Julie Stal-Le Cardinal ${ }^{2}$ \\ ${ }^{1}$ IAE-Paris, University Paris1 Panthéon-Sorbonne, 21, rue Broca, 75005 Paris \\ divine.iae@univ-paris1.fr \\ ${ }^{2}$ Ecole Centrale Paris, Industrial Engineering Department, \\ Grande Voie des Vignes, 92295 Chatenay Malabry Cedex, France \\ julie.le-cardinal@ecp.fr
}

\begin{abstract}
This research highlights the differences of the adoption of collaborative tools between one European and one emerging country in Asia. Based on the Adaptive Structuration Theory and the Technology Spirit concept, it uses a three dimensional model focused on both internal and external collaboration. 18 tools were surveyed in a sample of 75 managers of large companies with more than 1000 employees. The results show a wider external collaboration in the emerging country, particularly in the dimensions of actor's satisfaction and flexible frontier. Internal collaboration is more developed in both countries, but mainly in the dimension of value creation. The paper illustrates and adapts the theory in a high tech web 2.0 environment. Managerial implications are suggested in collaboration practices and measurements.
\end{abstract}

Keywords: Collaborative networks, collaborative tools, collaborative behavior, technology adoption, community management, web 2.0.

\section{Introduction}

Assuming that the e-collaboration practices are today a key factor of management success, this paper focuses on the differences of the adoption of collaborative technologies between two countries. The adoption of collaborative tools is considered as performance indicator, as it shows the transformation of relations to the virtual mode and the capacity to adapt to its new dynamics. The research aims to achieve a step forward in understanding collaboration behavior in order to help face future societal challenges. It also tackles the problem of the usual separation of the dual management of collaboration know-how: this competence is necessary to internal virtual teams and to external customer brand communities' management and marketing managers are major contributors to both. The literature until now has proposed several measurements, but no one covers the large range of tools internal as well as external, and gives an understanding of behavior. With a metrics of the use in 
a sample of large companies and the concepts of the Adaptive Structuration Theory, we will give an insight of the difference of behavior in two countries. In the first part, this paper shows up research results concerning technology adoption in collaborative activities, and underlines theories which point out the impact of adoption of tools. In the second part, the design of the research is detailed, including the sample of large companies from one emerging and one European country, the information collect methodology and its' treatment. The last part gives the findings of the research with a gap analysis of 18 collaborative tools. It compares the close internal and very different external uses between the two countries, in favor of the emerging country. It is completed by a three dimensional local vision of virtual teams and communities, based on the Technology Spirit concept, which explains this gap. The last part lists the contributions and suggests large companies' practical implications of the research.

\section{Current Understanding in the Literature and Research Question}

Since 1995, the Gartner Group has published a report on the global adoption of emerging technologies, summarized in the Hype curve [8] (Fenn, 1995). The adoption or appropriation is the process of actions documenting the use of technology [14] (Majchrzak et al., 2000). This report includes a few collaborative tools, such as the wiki or the blog, but lacks many of them, as it is focused on new technologies only. It does not provide country comparison. In 2000 a methodology to create a technology readiness index (TRI) was proposed [19] (Parasuraman, 2000). It uses qualitative questionnaires for each technology adoption analyzed. In 2008 the European Union published an e-business adoption index which takes into account mainly online revenue and ignores the collaboration. Models of e-collaboration have been published, based on three media richness levels [10] (Heidecke, 2009), or on virtual groups' links between electronic collaboration and factors such as electronic information sharing and exploitation capability [11] (Ko, 2009) or internal factors and economic external factors [13] (Madlberger, 2009). Another model has emerged from the network pictures concept, that is the managers' surroundings representation, a distant concept to communities, but which is close to collaboration. The proposed factors of pictures which influence behaviors are mainly power, followed by dynamics, broadness and indirectness [2] (Corsaro, 2011). Closer to the tools, the cooperation model based on the efficiency of collaborative tools must be mentioned [1] (Baker, 2002). This model makes differences between tools with cognitive factors: the ability of symmetry of the roles, the members' agreement visibility, and the progress in alignment in phases. These qualitative models and their outcomes are incomplete, due to the explosion of more than 150 collaborative tools [9] (Good, 2011) and the industry dynamics. Today, the abundant web analytics information provides large volume of data from the different web 2.0 tools separately [15] (Malo, 2009), without global internal and external collaboration vision.

Another authors presents new methods to support collaboration for virtual teams. [20, 21] (Schumacher, 2009 and 2012) tool consists in the implementation of an 
Aided Competence Management for Virtual Team Building System which features recommendations, guidelines and practices for virtual team building adapted at micro level to the requirements of each specific organization.

Based at macro level, the research question of this paper is "What are the differences of collaborative technology adoption in both internal and external usage between two given countries?"

This objective makes it necessary to identify the most used tools, and measure their use with a quantitative sample, which the present research did not do. While the internal collaborative practices are necessary in large multinational companies, they are a privileged field. The Adaptive Structuration Theory (AST) helps to understand the impact of technology adoption on behaviors. The AST [4] (DeSanctis, Poole, 1994) considers that there is a mutual interaction between agent's behavior and the system, which includes the technology environment. Later researches [17, 18] (Orlikowski, 1992 and 2000) [16] (Nikas, 2009) complemented it and see the adoption of tools as a key activity in the process of structuration of the virtual teams or communities. The adoption of technologies generates new behavior in specific directions, the technology spirits, which correspond to the initial intents of their designers. This research will identify, evaluate and compare the technology spirits and corresponding behavior in two countries.

In this perspective, the choice and use of tools provides information to unable the understanding of the qualitative differences of collaboration behavior between countries.

\section{$3 \quad$ Research Design}

Our research design to evaluate practices is made possible with the AST. Collaborative network projects need tools and reciprocally the collaborative tools generate innovative practices. The speed of adoption of the tools gives a measurement of the network potential capability. Applying the Adaptive Structuration Theory, the choice of the tools made by the managers of project virtual teams or customer communities reveals the type of technology spirit, and reciprocally, the present use of the tools develops the intent. The methodology is based on a comparative analysis of the use and probability of use of 18 tools by two samples of marketing managers. The tools are listed in Table 2. The Marketing Managers work in companies of more than 1000 employees: a first sample of 54 based in France and a second of 21 in Vietnam. They are in an ideal position for this research, as their job includes being members of virtual teams and knowing the tools used with their company's customers. The interviews aimed at listing the collaborative tools in use in their virtual teams and with customer communities. Interviewees were asked to say whether or not these tools were commonly used (yes-no) and their estimation of the probability of use if they were available (0-10) with comments. The information collected provides an adoption level of each tool. The weighed addition of all the tools use or probability to use gives global internal and external collaboration levels to each sample. The adoption pace measurement is then static (the use) and dynamic (the difference 
between use and probability to use). A correlation is calculated between the tools used in both countries, in order to measure divergences not only in intensity of use, but in choices. In a second information treatment step, we will use the model of classification of tools conducted by the authors [5, 6] (Divine, 2010 and 2012). It is a statistical analysis using principal component analysis and correlation index to identify groups of tools on the same database. It shows three classes, corresponding to three technology spirits: the value addition to the virtual team or community (VA), the actors' satisfaction (AS), and the flexible frontier (FF). The two first intents are directly linked to the Actors Theory [3] (Crozier, 1977) which demonstrates that the organization members' behavior is not only explained by their value addition to the organization, but also by their personal strategy and satisfaction. The last intent is linked to the virtuality, i. e. here distance collaboration, which allows a different perspective of virtual groups, with the wish or not to extend its frontiers. The category of value creation tools includes web conferencing, rating, commenting, sharing, wiki, remote control, pooling, posting, forum, LMS and partner's blog. The actors' satisfaction tools are the blog, rich directory, commenting, chat, tag, RSS and forum. The flexible frontier tools are the microblogging, the rich media, social networks and forum. The calculation concluded that commenting and forum are in several categories. In the tables of this paper the different tools are grouped in these categories. An interpretation of the qualitative differences between French and Vietnamese collaboration is made.

\section{$4 \quad$ Findings}

Despite a common level of interest internally as well as externally, we see in Table 1 a large gap in current use of the tools. The internal use of the collaborative tools is unequal in favor of Vietnam, whereas the external use shows an even larger difference. Large companies tend to set up worldwide internal communication modes integrated into their marketing procedures. On the opposite side, more freedom is given to local marketing customer communication patterns. Vietnam which has fewer marketing traditions and less marketing budget has taken the opportunity of this low cost customer media faster.

Table 1. Comparison of internal and external use and interest of Vietnam and France

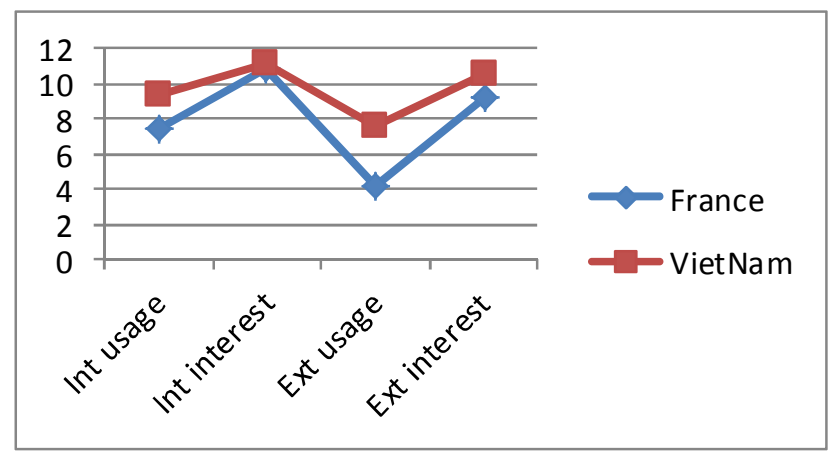


The insight into the different tools' internal use is given in Table 2. These practices which concern the management of marketing projects, show a $25 \%$ difference between the two countries in the intensity of use; 9.3 tools are used on average in Vietnam against 7.4 only in France. The correlation index is .70 in the type of tools between the two countries, showing some parallelism. Ten tools are used more than $10 \%$ in Vietnam, and one tool only in France. Web conference, social media, and document sharing are among the tools which are more commonly used internally in Vietnam. The interest level is high for 11 tools and identical for the two countries, showing room for more internal collaboration. We can conclude that in terms of collaboration practices, the internal marketing processes will become close when projects have a worldwide scope.

Table 2. Comparison of internal use in virtual teams of tools between Vietnam and France

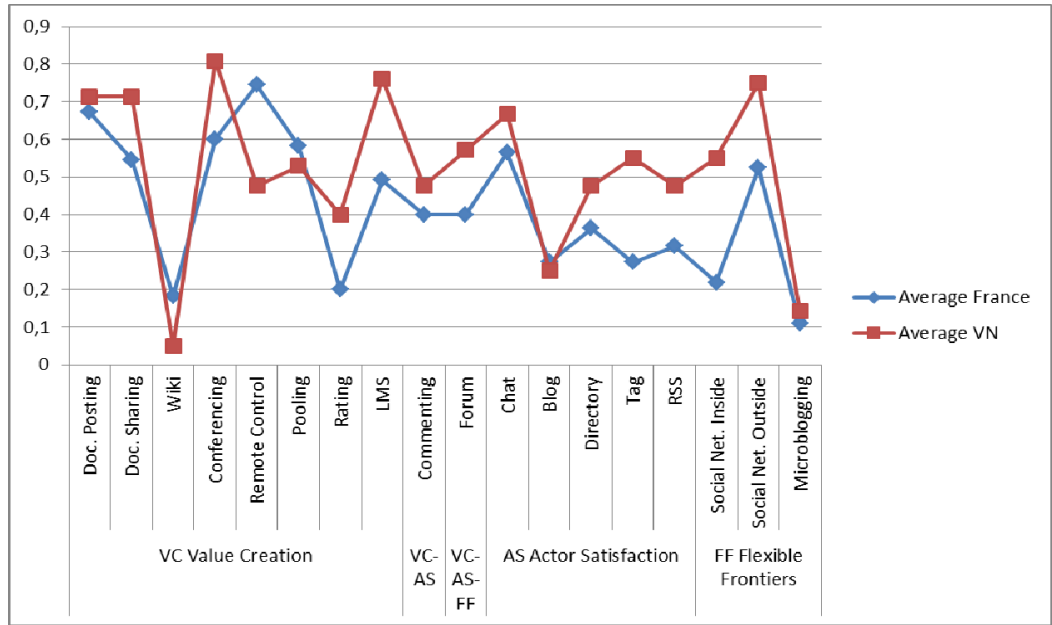

Table 3. Comparison of external use with customers of tools in Vietnam and France

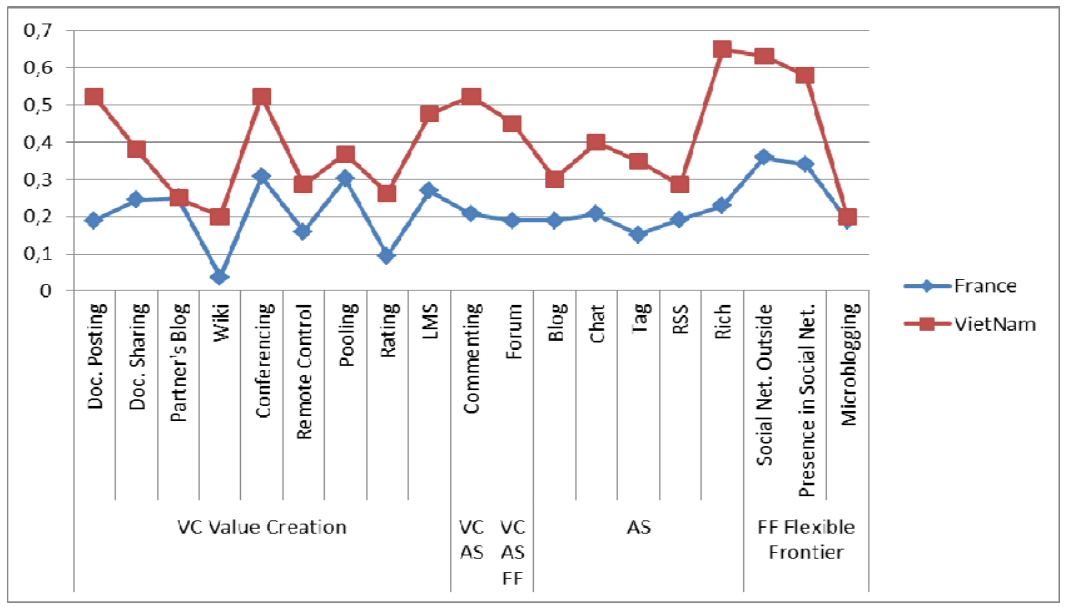


The external use of collaborative tools with customers is very different. The emerging country performs much better than the European country. This concerns all opportunities of interactive collaboration, between customers and customers with the brand. Much fewer tools are used externally, 4.1 on average in France, and 7.6 in Vietnam. The correlation between the choices of tools is .65 , showing a wider gap and more different local choices. In terms of use intensity, fifteen tools are used more than $10 \%$ in Vietnam than in France. In terms of use probability, 9.2 tools are targeted in France, a huge jump compared to 4.1 today. In Vietnam 10.5 tools are targeted, a better score, but a lower jump compared to 7.6. The tools with the biggest gaps are commenting, posting, social network and rich media, which are also the most popular. Six tools are already used by more than half of the sample in Vietnam, and none in France.

We can mention that the correlation index between internal and external collaboration is .79 for the total sample: the collaboration is more developed internally, but it is correlated to external practices. It is a dual culture inside the organization as well as with customers.

The table 4 gives the split of the tools use between the three dimensions, in both internal and external use.

Table 4. Comparison of internal and external three dimensions: Value Creation, Actor Satisfaction and Flexible Frontier

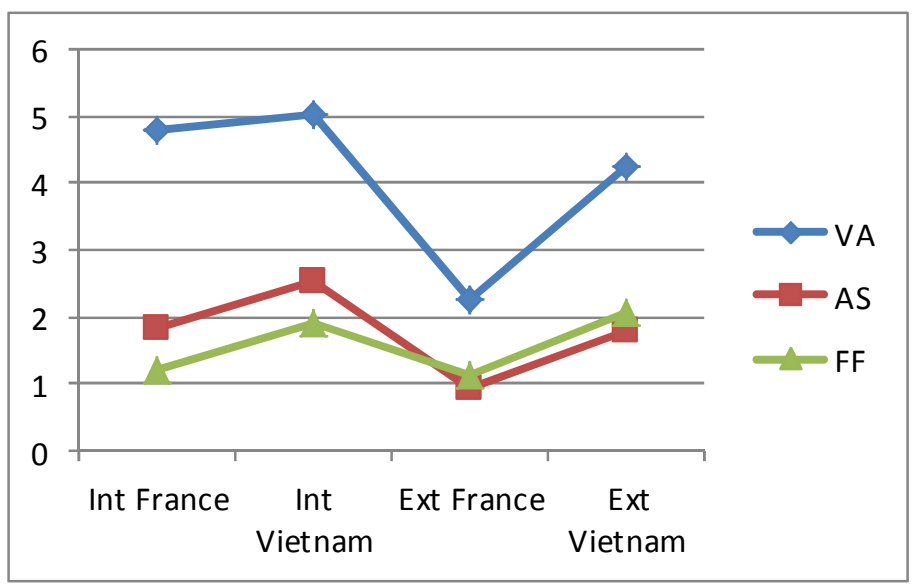

The results show a wider external collaboration in the emerging country, particularly in the dimensions of actor's satisfaction and flexible frontier. Internal collaboration is more developed in both countries, but mainly in the dimension of value creation. The most important gap is in the value creation in external usage: the perception in the emerging country of the web 2.0 contribution to the branding mechanics is stronger. 


\section{Outcomes and Discussion: Theoretical and Managerial Implications}

This research reveals a specific perspective of e-collaboration based on the tools' use and a dual internal and external vision. It illustrates the AST with an identification of three technology spirits and explains the three behaviors levels in two countries. This outcome provides a model which can be extended to other countries, groups or organizations. This model is flexible to different types of tools, can accept new ones. It is can be extended from internal and external use to new mix use in virtual structures, where structures mix members from different organizations and communities [7] (Fahy, 2007).

The research demonstrates that the large companies' management should focus on some emerging countries e-collaboration with a dual vision of tools. On the one hand, Vietnam shows a collaborative intimacy with customers which will create a considerable impact on the future. The constant dialog with the brand and between customers developed by the e-collaboration is a source of good understanding, reactivity and secure innovation success [12] (MacCormack, 2008). On the other hand, due to the correlation between internal and external use, their position will accelerate their internal use and collaboration performance.

The technology adoption is the layout for new internet behavior. Large companies' Innovation Managers should gain from the following managerial propositions:

- Use the emerging countries as the inspiring area of the collaborative tools adoption process.

- Develop more employee and customer satisfaction and practices of frontier extension based on the tools of this class in European countries

- Track and set a target of internal and external tools use

The pace of adoption of collaborative tools in Vietnam is due to a start-from-zero beneficial status, comparable to pure-players start-ups in old industries. The extension of the Vietnamese success result to other emerging countries can be discussed, so that other measurements and needed. This research will go further towards the directions shown by the collaborative tools evolution. New tools and new behavior will appear, and other researches at micro level to optimize choices of tools. In order to trace this evolution, our index of collaboration activity is planned to be maintained and results provided as an operational benchmark to managers.

\section{References}

1. Baker, M.: Forms of cooperation in dyadic problem-solving. In: Salembier, P., Benchekron, T.H. (eds.) Cooperation and Complexity in Sociotechnical Systems, Lavoisier, vol. 16, pp. 587-620 (2002)

2. Corsaro, D., Ramos, C., Henneberg, S.C., Naudé, P.: Actor Network Pictures and Networking Activities in Business Networks: An Experimental Study. Industrial Marketing Management 40(6), 919-932 (2011) 
3. Crozier, M., Friedberg, E.: L'acteur et le système, Le seuil, Paris (1977)

4. DeSanctis, G., Poole, M.: Capturing the Complexity in Advanced Technology Use: Adaptive Structuration Theory. Organization Science 5(2), 121-147 (1994)

5. Diviné, M., Schumacher, M., Le-Cardinal, J.: Learning Virtual Teams: How to Design a Set of Web 2.0 Tools. International Journal of Technology Management, Acceptance notice (2010)

6. Diviné, M.: Virtual Customer Communities: e-Collaboration is Not a Given. A Threedimensional Model Based on Web 2.0 Tools; Industrial Marketing Management Journal, IMM (submitted in February 2012)

7. Fahy, M., Feller, J., Finnegan, P., Murphy, C.: Complexity and context: Emerging forms of collaborative inter-organizational systems. Journal of Information Technology Theory and Application 8(4), 1-19 (2007)

8. Fenn, J.: When to Leap on the Hype Cycle. Gartner Group publications (1995)

9. Good, R.: Best Online Collaboration Tools 2008 - The Collaborative Map (2008),

http: / /www. masternewmedia.org/best-online-collaborationtools-2008-the-collaborative/\#ixzz1IZpWVLYU

10. Heidecke, F., Back, A.: A reference model for e-collaboration within the dispersed sales force training process in multinational companies. International Journal of eCollaboration 5(1), 32-46 (2009)

11. Ko, I., Olfman, L., Choi, S.: The Impacts of Electronic Collaboration and Information Exploitation Capability on Firm Performance: Focusing on Suppliers using BuyerDominated Inter-Organizational Information Systems. International Journal of eCollaboration 5(2), 1-17 (2009)

12. MacCormack, A., Forbath, T.: Learning the fine art of global collaboration. Harward Business Review 86(1), 24-26 (2008)

13. Madlberger, M.: What Drives Firms to Engage in Interorganizational Information Sharing in Supply Chain Management? International Journal of e-Collaboration 5(2), 18-42 (2009)

14. Majchrzak, A., Rice, R., Malhotra, E., King, N.: Technology adaptation: The case of a computer-supported inter-organizational virtual team. MIS Quarterly 24(4), 569-600 (2000)

15. Malo, N., Warren, J.: Web Analytics, Eyrolles, ed. d'Organisation (2009)

16. Nikas, A., Poulymenakou, A.: Technology Adaptation: Capturing the Appropriation Dynamics of Web-based Collaboration Support in a Project Team. International Journal of e-Collaboration 4(2) (January-March 2008)

17. Orlikowski, W.J.: The duality of technology: rethinking the concept of technology in organizations. Organization Science 3(3), 398-429 (1992)

18. Orlikowski, W.: Using technology and constituting structures: A practice lens for studying technology in organizations. Organizational Science 11(4), 404-428 (2000)

19. Parasuraman, A.: Technology readiness index (TRI): A multiple-item scale to measure readiness to embrace new technologies. Journal of Service Research 2(4), 307-320 (2000)

20. Schumacher, M., Diviné, M., Stal- Le Cardinal, J., Bocquet, J.C.: Virtual Teams Challenging Human and Technical Web 2.0 dimensions. International Journal of Networking and Virtual Organisations; Plüss, A., Huber, C.: Virtual Project Management: Collaboration and Leadership, Special Edition, accepted September 2010 (Publication scheduled for, 2012)

21. Schumacher, M., Stal-Le Cardinal, J., Bocquet, J.-C.: Towards a Methodology for Managing Competencies in Virtual Teams - A Systemic Approach. In: Camarinha-Matos, L.M., Paraskakis, I., Afsarmanesh, H. (eds.) PRO-VE 2009. IFIP AICT, vol. 307, pp. 235244. Springer, Heidelberg (2009) 